\title{
Layer Character of Wind Fields over the Simplified Gorge Terrain
}

\author{
Peng $\mathrm{Hu}^{1}$, Fanrong Xue ${ }^{1}$, Yan Han ${ }^{1, *}$ and Shuqian $\mathrm{Liu}^{2}$ \\ ${ }^{1}$ School of Civil Engineering and Architecture, Changsha University of Science \& Technology, Changsha 410114, China \\ ${ }^{2}$ Department of Civil and Environmental Engineering, Louisiana State University, Baton Rouge, 70803, United States
}

Received 10 May 2017; Accepted 1 August 2017

\begin{abstract}
Characteristics of wind fields over gorge terrains are important not only for pollution dispersion and forest fires but also for civil structures. However, current studies are aimed only at specific gorge terrains. Thus, limited references are available for other engineering practices. Four V-shaped simplified gorge terrains were modeled in the computational domain to investigate the fundamental information of wind fields over gorge terrains, especially the layer character of the wind fields over gorge terrains. The values of mean wind speed and turbulence intensity were analyzed based on the numerical simulations on the wind fields over the four simplified gorges, and the method to calculate the height of the gorge inner layer was proposed. Results show that the wind fields over the simplified gorge terrains can be divided into two layers in the vertical direction, that is, the gorge inner layer and gorge outer layer. This finding proves that the layer character of wind fields exists in gorge terrains. The heights of the gorge inner layer are $0.242 \mathrm{~m}, 0.224 \mathrm{~m}, 0.215 \mathrm{~m}$, and $0.208 \mathrm{~m}$, respectively, which correspond to the gorge terrains with included angles of $80^{\circ}, 100^{\circ}, 120^{\circ}$, and $140^{\circ}$. This result implies that the smaller the included angle of the gorge terrain is, the higher the gorge inner layer becomes. The proposed method to calculate the height of the gorge inner layer was proved to be accurate, indicating that the derivation process is reasonable and reliable. The study provides new insights on investigating the characteristics of wind fields over gorge terrains.
\end{abstract}

Keywords: Layer character, Wind fields, Simplified gorge, Numerical simulation

\section{Introduction}

Long-span bridges located in the mountain-gorge terrains always straddle V-shaped deep-cutting gorges [1]. Thus, the characteristics of wind fields at the above bridge sites will be remarkably influenced by the deep-cutting gorge terrains, and the wind fields around the bridge main beam and bridge tower are extremely complicated [2]. In the literature, the characteristics of wind fields over the above gorge terrains have been studied, and they are important not only for pollution dispersion and forest fires but also for civil structures [3]. However, the current design specifications and standards [4] focus on flat and homogeneous terrain rather than on complex terrain, which are not applicable for real engineering practices [5]. Therefore, the wind fields over gorge terrains should be urgently investigated.

The wind fields over gorge terrains can be investigated via field measurements [6], wind tunnel tests [7], and computational fluid dynamics (CFD) numerical simulations [8]. Previous studies are usually aimed at the characteristics of wind fields over specific gorge terrains, such as the studies by Wharton et al. [9] and Li et al. [10]. However, the conclusions of wind fields over the above specific gorge terrains are different from each other because the geometry shapes of the gorges are different. On the one hand, it is very

\footnotetext{
*E-mail address: ce_hanyan@163.com

ISSN: $1791-2377$ @ 2017 Eastern Macedonia and Thrace Institute of Technology. All rights reserved. doi:10.25103/jestr.104.13
}

difficult to obtain fundamental information from the above specific gorge terrains. On the other hand, various conclusions wind fields over the specific gorge terrains provide limited references for other engineering practices.

On the basis of the above analysis, this study examines the fundamental information about the characteristics of wind fields over the gorge terrains and then gains practical approaches to the application of real engineering practices.

\section{State of the art}

To investigate the fundamental characteristics of wind fields over the gorge terrains, Moraes et al. [11] studied the nighttime data collected at the bottom of a gorge located in southern Brazil. The analyzed quantities include momentum and sensible heat fluxes, turbulence statistics and intermittency factors, and their relationship to the stability parameter. The results could provide fundamental nocturnal characteristics of wind fields at the gorge terrain. Magnago et al. [12] studied the spectral characteristics of surface boundary layer turbulence at the bottom of a narrow valley/gorge to gain fundamental understanding of air pollution dispersion in the complex terrain. The results revealed that the average spectra are better defined for mean winds parallel to the valley/gorge axis, and the peak of the vertical velocity spectra happens at smaller frequencies for winds parallel to the valley/gorge axis than when the winds are transversal to the valley. $\mathrm{Li}$ et al. [13] performed turbulence measurements at three vertical levels over a large 
gorge on the Loess Plateau. The power spectra of longitudinal and lateral wind speeds satisfy the $-5 / 3$ power law in the inertial subrange, but do not vary as observed in previous studies within the low frequency range. In addition, all the spectra and cospectra from the gorge direction show a height dependency over the three levels. Pal et al. [14] investigated the characteristics of vertical turbulent mixing and wind pattern change in a valley/gorge terrain to analyze the roles of atmospheric boundary layer depth and valleywind reversal on the temporal variation of particle number concentration at the valley/gorge terrain, which will be of benefit to study the fundamental meteorology and air quality in other valley/gorge terrains.

As for the characteristics of wind fields over the civil structures such as long-span bridges, Hui et al. [15-16] investigated the wind fields at a long-span bridge site adjacent to a high-steep mountain which is similar to a gorge terrain based on the 27 months' data collected at the CT8 mast and terrain model wind tunnel experiments. The variations of mean wind speed, wind power spectra, integral length scales, and coherences at the bridge site were obtained, providing accuracy parameters for the buffeting of the long-span bridge. More importantly, their studies can provide references for other long-span bridges in terms of study methods and variations of wind fields at the bridge site Fenerci et al. [17] developed a measurement system consisting of 20 accelerometers and 9 anemometers and used the long-term monitoring data of wind velocities and accelerations on a long-span bridge located in a gorge terrain to investigate the relationship between the wind-loading and responses. Results showed that the wind fields have large variability in the mean wind speed, mean wind direction, turbulence intensities, and length scales in the bridge site. Besides, the dynamic response of the bridge was governed by the low-frequency vibrations induced by wind loads. Li et al. $[10,18]$ studied the wind fields over a V-shaped deepcutting gorge where a super long suspension bridge with a main span of $1176 \mathrm{~m}$ straddles based on the wind tunnel tests. The results indicated that the profiles of mean wind speed in the gorge obviously change along the bridge main beam, and it cannot be simulated as a uniform wind speed profile. The height of measurement position and the shape of terrain on both sides of the gorge should be considered when analyzing these wind fields. The study conclusions can provide useful fundamental information about the variations of mean wind speed and other wind parameters for other gorge terrains with regard to qualitative analysis.

Although the above studies can provide some fundamental characteristics of wind fields over the gorge terrains in varying degrees, one common drawback is that previous studies are generally conducted based on the phenomenon description rather than mechanism analysis, which could hinder the usage in engineering practices. Li et al. [7] made an enormous bridge site terrain model in a large wind tunnel to investigate the fundamental characteristics of wind fields over the gorge terrains from the perspective of mechanism analysis. The bridge site is located in a typical deep-cutting gorge. Then, the mechanism tests with different test cases were carried out. The wind tunnel test results show that the profiles of perpendicular wind speed along the bridge main beam can be divided into two parts in the vertical direction, and the shapes of the wind speed profiles along the two bridge towers are much consistent with the power law or log law than those at the bridge main beam. From the above studies, it can be concluded that the characteristics of wind fields over the gorge terrain significantly change in the vertical direction, which indicates that the wind fields over the gorge terrain could be divided into two layers in the vertical direction. However, the layer character of the wind fields is far more complex and less well understood, and it should be further validated by more and typical gorge terrains.

To further study the fundamental wind characteristics over the gorge terrains, especially the layer character of the wind fields which probably have high value of practical application. Hu et al. [19-20] introduced a V-shaped simplified gorge, which was abstracted from several real deep-cutting gorges where long-span bridges usually straddle. Then, the wind fields including the mean wind speed, turbulence intensity, integral length scale, and wind power spectrum were investigated in a wind tunnel. The results show that compared with the oncoming wind, the wind speeds at the gorge center become larger, but the turbulence intensities and the longitudinal integral length scales become smaller. The wind fields over the gorge terrain can be approximately divided into two layers, that is, the gorge inner layer and the gorge outer layer. Obviously, the above results again prove that the wind fields over the gorge terrain can be divided into two layers, and these two layers can help analyze the wind fields more conveniently. However, previous studies did not further investigate the boundary between the two layers or provide the method to determine the ranges of these two layers.

The sections of this study are arranged as follows. In the third section, the study setups, models, and method were introduced. In the fourth section, the layer character of the wind fields over the gorge terrains was investigated. The heights of the gorge inner layer varying with the included angles of the gorge terrains were analyzed. Furthermore, the method to calculate the height of the gorge inner layer was proposed based on the log law model. In the fifth section, several main conclusions were presented.

\section{Methodology}

\subsection{Setup of the numerical simulations}

In this study, the simplified terrain models were made in a circular shape with certain heights. Here, a transition section was molded around the circular terrain to develop a more reasonable oncoming wind according to the study by $\mathrm{Hu}$ et al. [1]. Then, a V-shaped groove with certain included angle was cut along the center of the circular terrain to shape a simplified gorge terrain. Fig. 1 shows the final V-shaped simplified gorge terrain model.

Generally, the included angle of the gorge terrain is changeable in the real engineering practices. Therefore, four simplified gorge terrains were modeled in this study, as shown in Fig. 1. They were the simplified gorge terrains with included angles of $80^{\circ}, 100^{\circ}, 120^{\circ}$, and $140^{\circ}$, respectively, of which the heights were all $0.25 \mathrm{~m}$.

Many researchers have demonstrated that the surface roughness has obvious effects on the wind fields of the terrain. Cao and Tamura [21] found that the separation region of a rough hill extended further downstream, which could develop a larger reattachment length than a smooth hill. Considering that there exist many vegetation and trees on the surface of the real gorge that can create a certain surface roughness, many $10 \mathrm{~mm}$ cube elements were arranged in a staggered pattern above the terrain surface to model the real surface roughness appropriately, as shown in 
Fig. 2. This arrangement results in a roughness density equaling to $8.0 \%$.
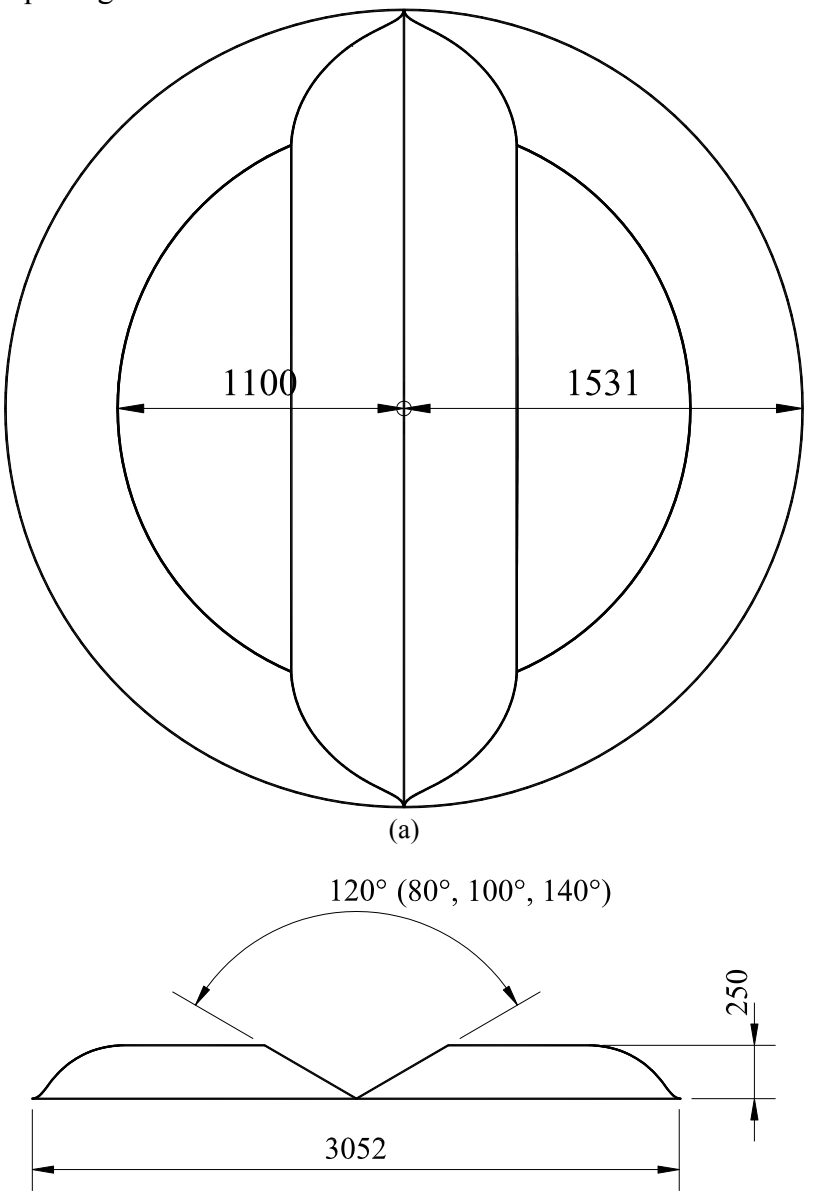

(b)

Fig. 1. Simplified gorge terrain models (Unit: mm). (a) Top view. (b) Side view

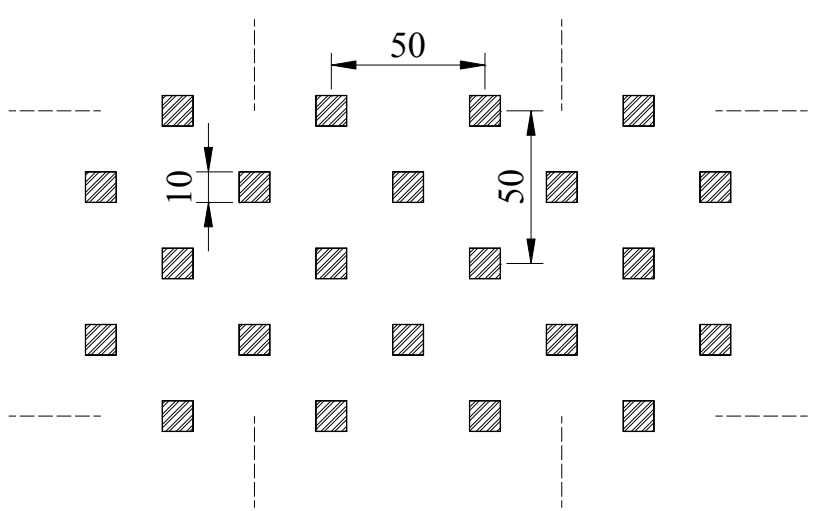

Fig. 2. Layout of cube elements above the terrain surface (Unit: $\mathrm{mm}$ )

The well-known CFD software ANSYS [22] was adopted to simulate the wind fields over the four simplified gorge terrains. Half of the terrain model was modeled according to the symmetry of the characteristics of wind fields induced by the oncoming wind flowing along the axis of each gorge terrain. The computational domain that was $18.0 \mathrm{~m}$ long $(x), 1.8 \mathrm{~m}$ wide $(z)$, and $3.0 \mathrm{~m}$ high $(y)$ was adopted. The distance from the wall-adjacent cell center to the bottom wall was $0.0005 \mathrm{~m}$, and the average value of $y+$ near the region where the measurement positions located were all approximately equal to 4.0. The grid sensitivity was analyzed by several comparative studies to further improve the precision of the numerical simulations. The total number of cells was about 6 million, which was fine enough for the present models. For the terrain model with height of $0.25 \mathrm{~m}$ and included angle of $120^{\circ}$, the numerical model of half of the simplified gorge terrain is shown in Fig. 3(a), and the grid generation is shown in Fig. 3(b).

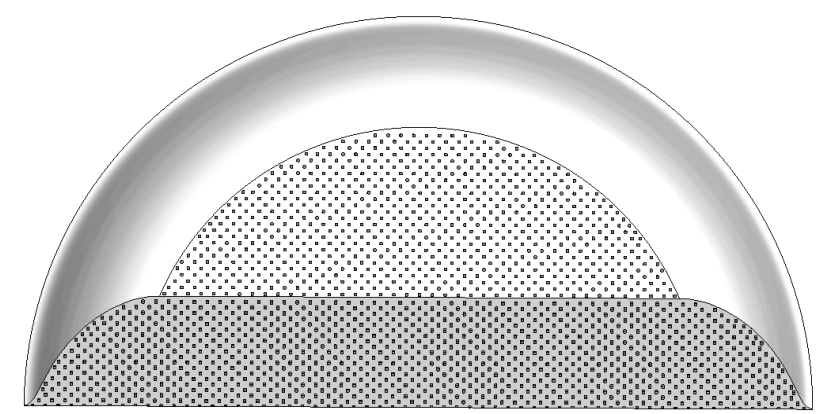

(a)

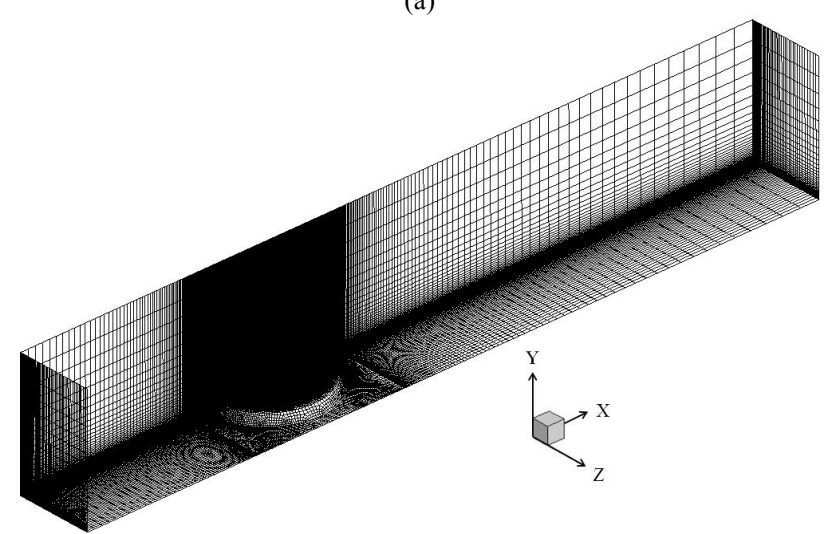

(b)

Fig. 3. Numerical model and grid generation for the terrain model. (a) Numerical model of half of the gorge terrain. (b) Grid generation

The SST $k$ - $\omega$ turbulence model was employed in this study. As for the boundary conditions, the velocity-inlet boundary condition was used at the inlet, and the characteristics of atmospheric boundary layer were modeled. The symmetry side was modeled as a symmetry condition. The top and the other side of the computational domain were set as a smooth wall, and at the outlet, the pressure-outlet boundary condition was applied. A rough smooth wall was modeled at the bottom of the computational domain. More details on the numerical simulations can be obtained in $\mathrm{Hu}$ et al. [20].

\subsection{Numerical simulations on the wind fields over the} gorge terrains with different included angles

Based on the above setups, the numerical simulations could be carried out. Figs. 4 and 5 show the values of mean wind speed and turbulence intensity at the gorge center with four included angles together with those at the inlet for comparison. From Fig. 4, we can observe that the values of mean wind speed at the gorge center with different included angles generally increase compared with those of the oncoming wind. In addition, with the included angle increasing, the mean wind speeds at the gorge center also increase. As for the turbulence intensity, the turbulence intensities at the gorge center are much smaller compared with those at the inlet. Besides, the values of the turbulence intensity tend to slightly decrease with the included angle of the gorge terrain increasing, as shown in Fig. 5. Furthermore, it can be seen that when the measurement positions are far away from the ground, the values of mean wind speed and 
turbulence intensity with different included angles all become close to each other, which implies that the effects of gorge terrain have little effects on the characteristics of wind fields over the gorge under the circumstances. Instead, the wind fields almost depend on the oncoming wind.

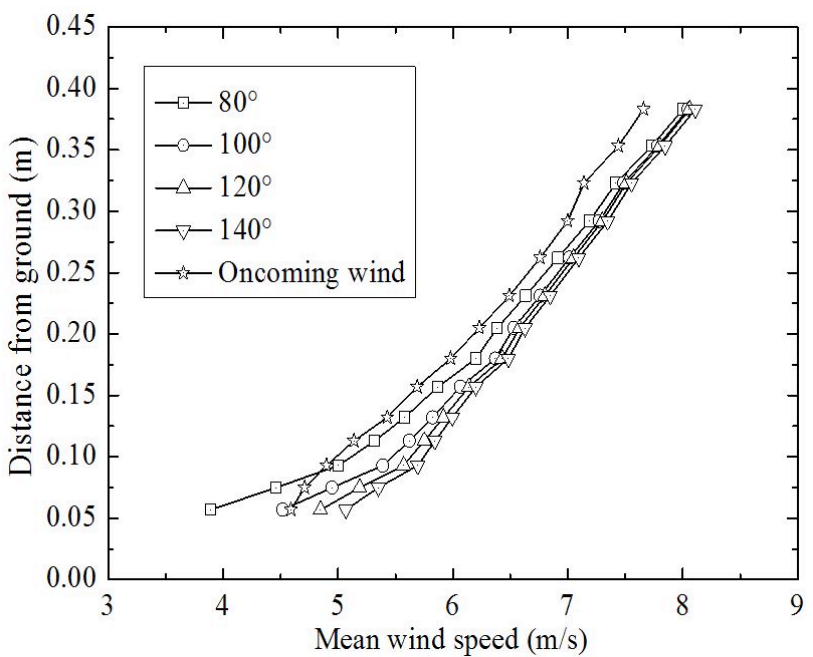

Fig. 4. Profiles of mean wind speed

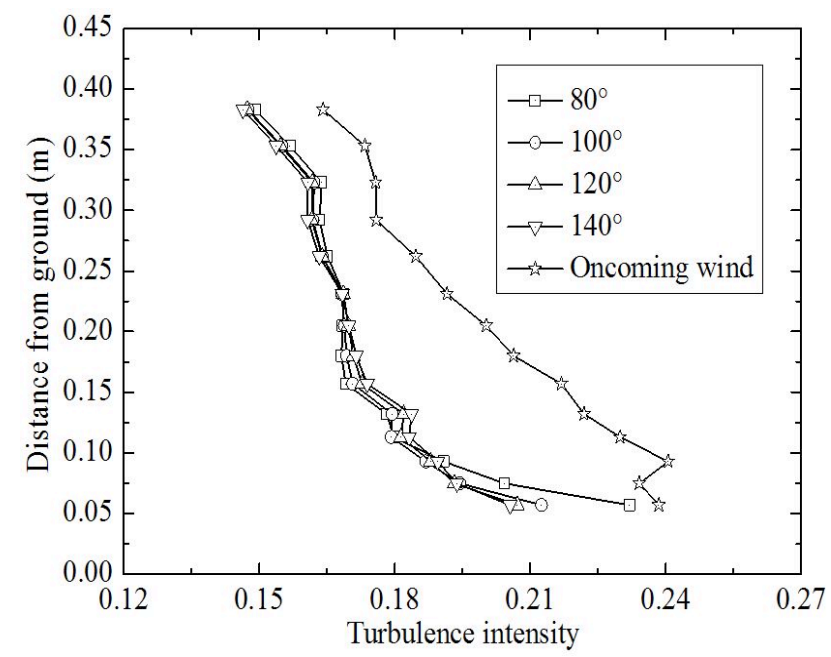

Fig. 5. Profiles of turbulence intensity

\section{Result Analysis and Discussion}

\subsection{Layer character of wind fields in the vertical direction}

To further address the changes of characteristics of wind fields at the gorge center compared with those of the oncoming wind, the ratios of mean wind speed and turbulence intensity at the gorge center to those of the oncoming wind are shown in Figs. 6 and 7, respectively. With the distances from the ground increasing, the ratios of mean wind speed first increase and then decrease but become stable at last. On the other hand, the ratios of turbulence intensity first decrease and then increase but also become stable finally. The wind fields over a flat plate can be divided into two layers, i.e., the inner shear layer produced by the viscous effects and the outer potential flow layer where the viscous effects can be ignored [23]. From the above, the wind fields over the gorge terrain can also be approximately divided into two layers, i.e., the gorge inner layer and the gorge outer layer. In the gorge inner layer, the wind fields are complicated due to the influences mainly caused by the two side slopes of the gorge terrain and due to the oncoming wind. In the gorge outer layer, the wind fields are almost dependent on the oncoming wind.

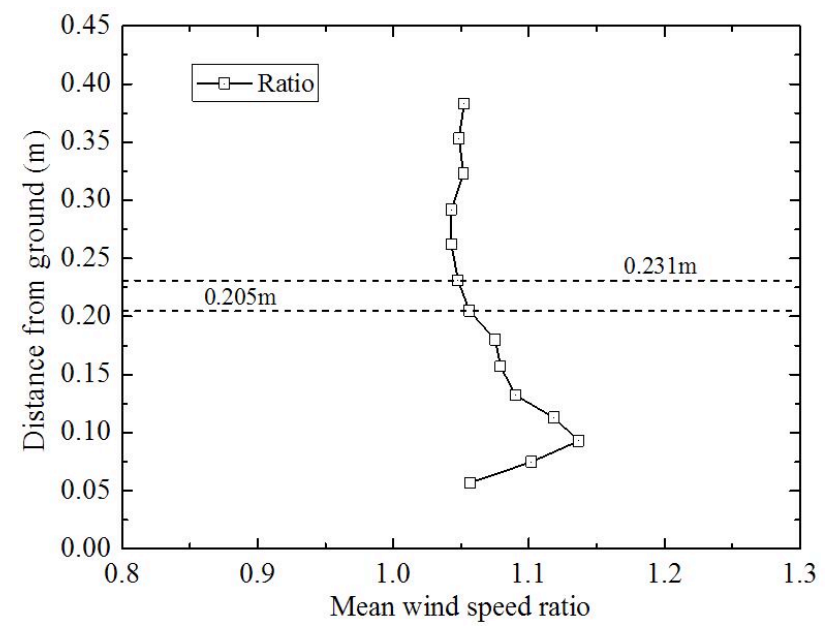

Fig. 6. Profiles of mean wind speed ratio

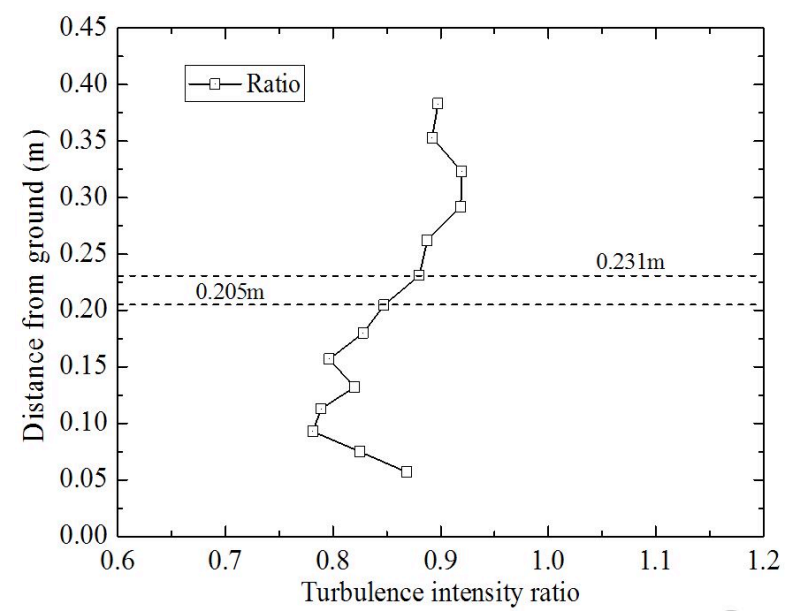

Fig. 7. Profiles of turbulence intensity ratio

For the present study, the gorge inner layer is about below the range of $0.205-0.231 \mathrm{~m}$, where the mean wind speeds accelerate, but the acceleration is not stable. In addition, the variations of the turbulence intensity fluctuate significantly. While in the gorge outer layer which is about above the range of $0.205-0.231 \mathrm{~m}$, the variations of the mean wind speed and turbulence intensity are stable and simple, as shown in Figs. 6 and 7. The reason is that the influences of the two side slopes of the gorge on the wind fields in the gorge outer layer are small, and the wind fields in the gorge outer layer mainly depend on the oncoming wind fields. As a result, the ratios of mean wind speed and turbulence intensity in the gorge outer layer are approximately 1.0 . From the above analysis, we can conclude that it is very convenient to investigate the characteristics of wind fields over civil structures, which are located in the gorge outer layer, because the wind fields in such circumstances are very stable and simple.

Similarly, the values of mean wind speed ratio and turbulence intensity ratio for other terrain models can also be obtained from Figs. 4 and 5. To make a better comparison, these two kinds of ratios for all the four terrain models are shown in Figs. 8 and 9. The boundary between the gorge inner layer and the gorge outer layer are very difficult to differentiate from these two figures. The possible reason is 
that the differences of the height between the two layers are very small, and it cannot be demonstrated clearly in Figs. 8 and 9. Therefore, an appropriate method should be proposed to determine the boundary between the two layers quantitatively.

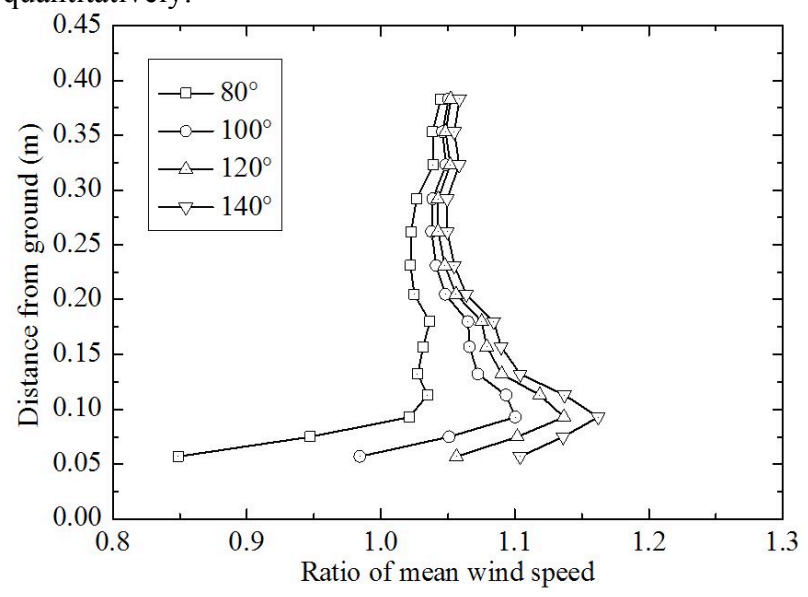

Fig. 8. Profiles of mean wind speed at the gorge center with different included angles

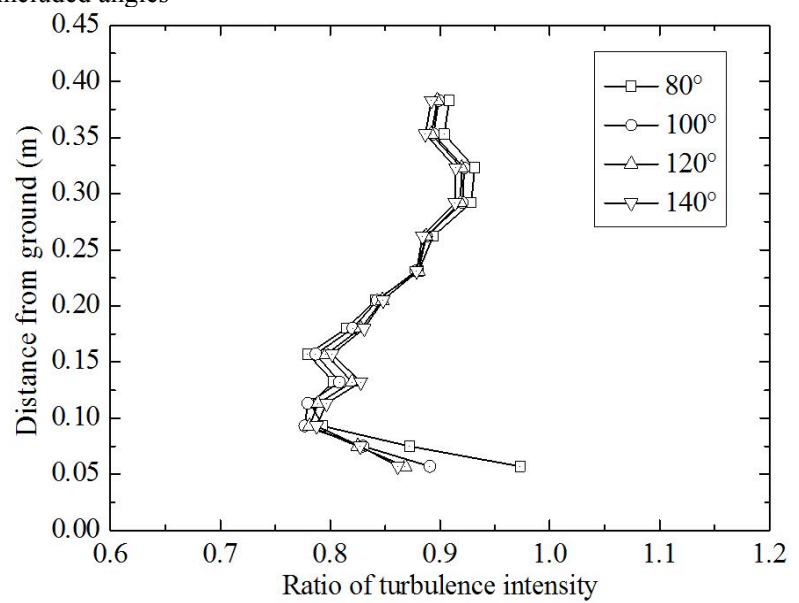

Fig. 9. Profiles of turbulence intensity at the gorge center with different included angles

\subsection{Calculation method for the height of gorge inner layer \\ 4.2.1 Height of the gorge inner layer}

As discussed earlier, the variations of the mean wind speed and turbulence intensity are stable and simple when the measurement positions are above the range of $0.205-0.231$ $\mathrm{m}$. The range is then regarded as the boundary between the gorge inner layer and the gorge outer layer, and then it is also determined as the approximate height of the gorge inner layer. A parameter called mean square deviation (MSD) of the turbulent wind, which is equal to the value of mean wind speed multiplied by turbulence intensity, should be investigated to quantitatively analyze the height of the gorge inner layer. One reason is that the parameters of mean wind speed and turbulence intensity are both the basis to determine the range of the boundary between the two layers or the height of the gorge inner layer as discussed earlier.

The profiles of MSD of the turbulent wind at the gorge center with different included angles together with that of the oncoming wind are shown in Fig. 10. It can be seen that the values of MSD at the gorge center are all smaller than those of the oncoming wind. Furthermore, the smaller the included angle of the gorge is, the smaller the values of MSD at the gorge center become, which indicates that the influences caused by the two side slopes of the gorge become more significant when the included angle of the gorge become smaller. Therefore, it is reasonable to use the relative ratios of the MSD at the gorge center to those of the oncoming wind to quantitatively determine the height of the gorge inner layer.

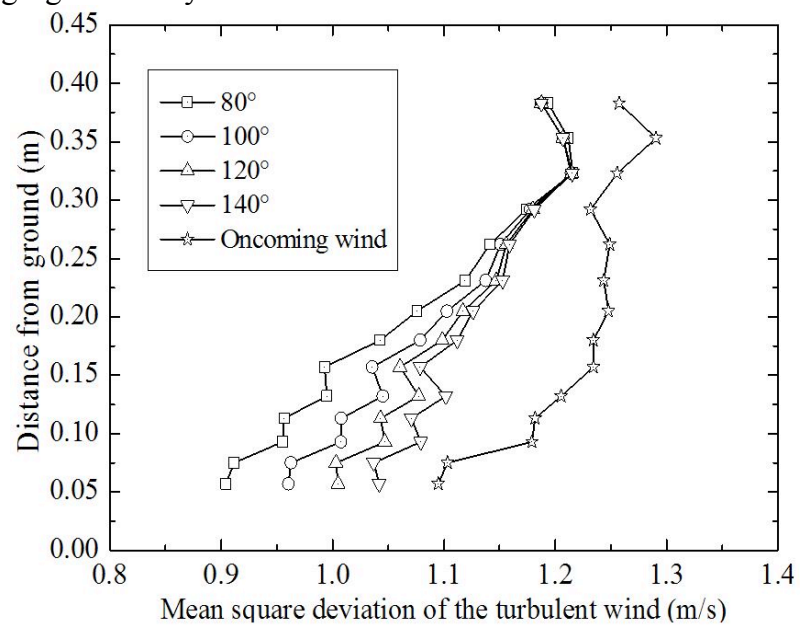

Fig. 10. Profiles of mean square deviation at the gorge center and at the oncoming wind

The relative ratios (refer to absolute values) of the MSD at the gorge center to those of the oncoming wind are shown in Fig. 11. It can be observed that the curves of the relative ratio of the MSD are not smooth due to the unsmoothed profiles of the mean wind speed and turbulence intensity (shown in Figs. 4 and 5), and the values of the relative ratios of the MSD generally decrease with the increase of the heights of measurement positions. More importantly, the relative ratio of MSD defined in the present study equals the relative error of MSD in a mathematical sense. The relative error equal to $5 \%$ is regarded as an acceptable value in real application. Obviously, the relative ratio equal to $5 \%$ is very small that it cannot be taken as the reference value to determine the boundary between the two layers or the height of the gorge inner layer. Considering that the boundary between the two layers is in the range of $0.205-0.231 \mathrm{~m}$ for the terrain model with height of $0.25 \mathrm{~m}$ and included angle of $120^{\circ}$, the reference value of the relative ratio for the present study should be set as $9.5 \%$, as shown in Fig. 11 . Then, the height of the gorge inner layer can be determined quantitatively. The values of the height are $0.242 \mathrm{~m}, 0.224 \mathrm{~m}$, $0.215 \mathrm{~m}$, and $0.208 \mathrm{~m}$ for the gorge terrains with included angles of $80^{\circ}, 100^{\circ}, 120^{\circ}$, and $140^{\circ}$, respectively, which corresponds to the $0.968,0.896,0.860$ and 0.832 times of the gorge height.

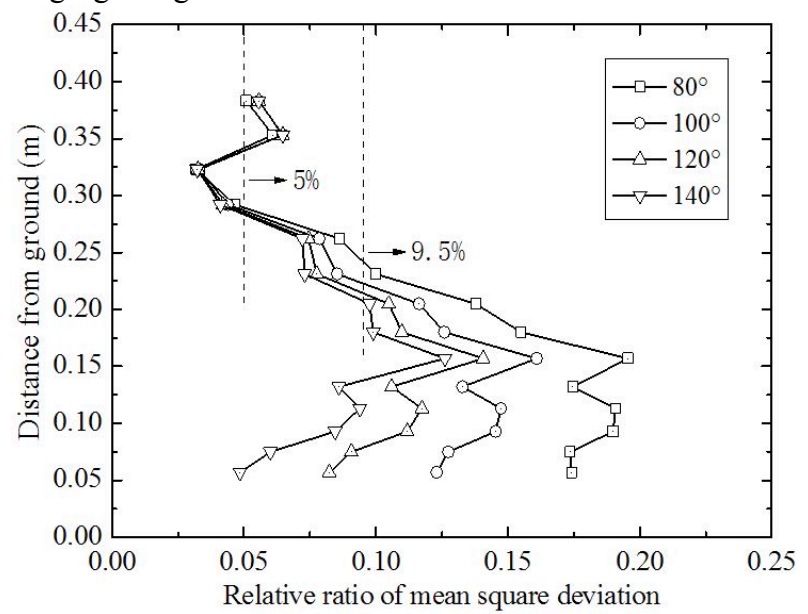

Fig. 11. Relative ratios (refer to absolute values) of the mean square deviation 


\subsubsection{Proposed method to calculate the height of gorge} inner layer

Because the curves of the profiles of turbulence intensity and MSD are both not smooth, as shown in Figs. 5 and 10, they cannot be fitted by some functions with high accuracy. However, the profile of mean wind speed seems to be fitted by the log law or power law model [24]. From the above analysis, the mean wind speed is the most suitable parameter to quantitatively calculate the height of the gorge inner layer. Generally, the profile of mean wind speed is always expressed by the log law when involving the theoretical derivation. According to log law model, the expressions of the profiles of mean wind speed at the gorge center and at the oncoming wind denoted by $U_{g}$ and $U_{i}$, respectively, can be expressed as Eqs. (1) and (2):

$U_{g}=\frac{u_{*_{g}}}{K} \ln \left(\frac{z}{z_{0 g}}\right)$

$U_{i}=\frac{u_{*_{i}}}{K} \ln \left(\frac{z}{z_{0 i}}\right)$

where $K$ is the Karman constant; $u_{*_{g}}$ and $u_{*_{i}}$ are the friction velocity at the gorge center and at the oncoming wind, respectively; $z$ is the height from the ground; $z_{0 g}$ and $z_{0 i}$ are surface roughness length at the gorge center and at the oncoming wind, respectively. Here, the parameters $u_{*_{g}}, u_{*_{i}}, z_{0 g}$, and $z_{0 i}$ can be obtained by fitting the $\log$ law model to the profiles of mean wind speed.

The ratio of $U_{g}$ to $U_{i}$ can be obtained from Eqs. (1) and (2), and it yields

$$
\begin{aligned}
\frac{U_{g}}{U_{i}}=\frac{u_{*_{g}}}{u_{*_{i}}} \cdot \frac{\ln \left(z / z_{0 g}\right)}{\ln \left(z / z_{0 i}\right)} \\
=\frac{u_{*_{g}}}{u_{*_{i}}} \cdot\left(1+\frac{\ln \left(z_{0 i} / z_{0 g}\right)}{\ln \left(z / z_{0 i}\right)}\right)
\end{aligned}
$$

Rewriting Eq. (3) yields

$$
\ln \left(\frac{z}{z_{0 i}}\right)=\frac{1}{\frac{U_{g}}{U_{i}} \cdot \frac{u_{*_{i}}}{u_{*_{g}}}-1} \cdot \ln \left(\frac{z_{0 i}}{z_{0 g}}\right)
$$

Simplifying Eq. (4) yields

$$
z=z_{0 i} \cdot\left(\frac{z_{0 i}}{z_{0 g}}\right)^{\frac{u_{i} u_{g}}{u_{g} u_{*_{i}}-u_{i} u_{z_{g}}}}
$$

From Eq. (5), the value of $z$ equals to the height of the gorge inner layer (denoted by $h$ ) when the power exponent of Eq. (5) takes an appropriate value. It should be noted that the Eq. (5) is derived only based on the parameter of mean wind speed. In fact, the gorge inner layer is defined based on the MSD, which includes the parameters of mean wind speed and turbulence intensity. Eq. (5) may be not accurate enough to calculate the height of gorge inner layer. From the above, the height of gorge inner layer could be approximately expressed according to Eq. (5), and it yields

$$
h=C_{h} \cdot z_{0 i}\left(\frac{z_{0 i}}{z_{0 g}}\right)^{\alpha}
$$

where $h$ is height of the gorge inner layer; $C_{h}$ is a coefficient; $\alpha$ is the power exponent.

From Eq. (6), the values of $C_{h}$ and $\alpha$ can be determined based on the above numerical results. The parameters of $z_{0 g}$ and $z_{0 i}$ changing with the gorge terrain model with different included angles are listed in Table 1. It can be seen from Table 1 that the smaller the included angle of the gorge is, the value of the surface roughness length $z_{0 g}$ becomes, which again proves that the influences caused by the two side slopes of the gorge become more significant when the included angle of the gorge become smaller, making the gorge inner layer higher.

Table 1. Parameters changing with the gorge terrains with four included angles

\begin{tabular}{c|c|c|c}
\hline Included angle $\left(^{\circ}\right)$ & $h(\mathrm{~m})$ & $z_{0 g}(\mathrm{~m})$ & $z_{0 i}(\mathrm{~m})$ \\
\hline 80 & 0.242 & 0.00734 & 0.00612 \\
\hline 100 & 0.224 & 0.00317 & 0.00612 \\
\hline 120 & 0.215 & 0.00166 & 0.00612 \\
\hline 140 & 0.208 & 0.00101 & 0.00612 \\
\hline
\end{tabular}

The fitted results of $C_{h}$ and $\alpha$ are shown in Fig. 12, in which the $x$-coordinate refers to the value of $z_{0 i} / z_{0 g}$ and the $y$-coordinate refers to the value of $h / z_{0 i}$. From Fig. 12, the value of $C_{h}$ equals to 38.8, and the value of $\alpha$ equals to 0.0765 . Note that the fitted parameter Adj.R-Square is 0.994 [25], which indicates that Eq. (6) is very accurate and reasonable to calculate the height of the gorge inner layer.

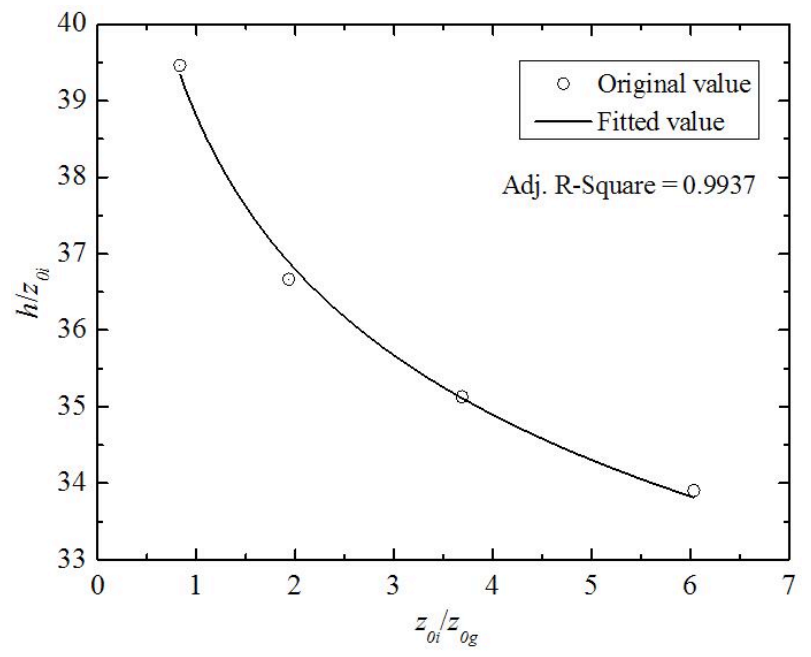

Fig.12. Fitted results of coefficients $C_{h}$ and $\alpha$

\section{Conclusions}

Four V-shaped simplified gorge terrains were introduced to further investigate the fundamental wind characteristics over the gorge terrains, especially the layer character of the wind fields. Through the CFD numerical simulation method, the values of mean wind speed and turbulence intensity over the four simplified gorges were analyzed, and a practicable method based on the log law model was proposed to 
calculate the height of the gorge inner layer. The following conclusions could be drawn:

(1) The wind fields over the gorge terrain can be divided into two layers in the vertical direction, that is, the gorge inner layer and gorge outer layer. Wind field variations are complex in the gorge inner layer and are stable and simple in the gorge outer layer.

(2) Based on the relative ratios of the mean square deviation, the heights of gorge inner layer for the gorge terrains with the included angles of $80^{\circ}, 100^{\circ}, 120^{\circ}$, and $140^{\circ}$ are determined quantitatively. They are $0.242 \mathrm{~m}, 0.224$ $\mathrm{m}, 0.215 \mathrm{~m}$, and $0.208 \mathrm{~m}$, respectively, which indicates that the influences caused by the two side slopes of the gorge become more significant when the included angle of the gorge becomes smaller.

(3) According to the log law model, the method to calculate the height of gorge inner layer was proposed, and it is proved that the method is very accurate and reasonable.

The definition of the gorge inner layer and gorge outer layer in this study can be very useful and convenient when investigating the wind fields over the gorge terrains. Furthermore, the proposed method to calculate the height of the gorge inner layer can provide a new idea to investigate the characteristics of wind fields over the civil structures located in a gorge terrain. For instance, when a civil structure is located in the gorge outer layer, its wind fields can be obtained more easily and more precisely, and the CFD numerical simulation method is practical. Inversely, when it is located in the gorge inner layer, its fields would be complicated, and the wind tunnel test method should be adopted. Although some progress has been made in this study, the gorge terrain models are all aimed at the simplified terrains, and the real gorge terrains are not addressed here. The layer character of the wind fields over the real gorge terrains should be focused on in future studies.

\section{Acknowledgements}

The study was supported by the Educational Commission of Hunan Province of China (Grant No. 17C0056).

This is an Open Access article distributed under the terms of the Creative Commons Attribution Licence

\section{References}

1. Hu, P., Li, Y. L., Huang, G. Q., Kang, R., Liao, H. L., "The appropriate shape of the boundary transition section for a mountaingorge terrain model in a wind tunnel test". Wind and Structures, 20(1), 2015, pp.15-36.

2. Li, Y. L., Hu, P., Cai, X. T., Tang, K., Liao, H. L., "Spatial distribution feature of wind fields over bridge site with a deepcutting gorge by numerical simulation method". The 13th International Conference on Wind Engineering, Amsterdam, Netherlands, 2011.

3. Maurizi, A., Palma, J. M. L. M., Castro, F. A., "Numerical simulation of the atmospheric flow in a mountainous region of the North of Portugal". Journal of Wind Engineering and Industrial Aerodynamics, 74-76, 1998, pp.219-228.

4. CCCC Highway Consultants CO., Ltd., "Wind-resistent design specification for highway bridges". Beijing: China Communications Press, China, 2004. (in Chinese)

5. Li, Y. L., Xu, X. Y., Zhang, M. J., Xu, Y. L., "Wind tunnel test and numerical simulation of wind characteristics at a bridge site in mountainous terrain". Advances in Structural Engineering, 20(8), 2017, pp.1223-1231.

6. Jiang, Y., Huang, G. Q., "Short-term wind speed prediction: hybrid of ensemble empirical mode decomposition, feature selection and error correction". Energy Conversion and Management, 144, 2017, pp.340-350.

7. Li, Y. L., Hu, P., Xu, X. Y., Qiu, J. J., "Wind characteristics at bridge site in a deep-cutting gorge by wind tunnel test". Journal of Wind Engineering and Industrial Aerodynamic, 160, 2017, pp.3046.

8. Sathyanadh, A., Prabha, T. V., Balaji, B., Resmi, E.A., Karipot, A., "Evaluation of WRF PBL parameterization schemes against direct observations during a dry event over the Ganges valley". Atmospheric Research, 193, 2017, pp.125-141.

9. Wharton, S., Ma, S., Baldocchi, D. D., Falk, M., Newman, J. F., Osuna, J. L., Bible, K., "Influence of regional nighttime atmospheric regimes on canopy turbulence and gradients at a closed and open forest in mountain-valley terrain". Agricultural and Forest Meteorology, 237-238, 2017, pp.18-29.

10. Li, C. G., Chen, Z. Q., Zhang, Z. T., Cheung, J. C. K., "Wind tunnel modeling of flow over mountainous valley terrain". Wind and Structures, 13(3), 2010, pp.275-292.

11. Moraes, O. L. L., Acevedo, O. C., Da Silva, R., Magnago, R., Siqueira, A. C., "Nocturnal surface-layer characteristics at the bottom of a valley". Boundary-Layer Meteorology, 112(1), 2004, pp.159-177.

12. Magnago, R., Moraes, O., Acevedo, O., "Turbulence velocity spectra dependence on the mean wind at the bottom of a valley". Physica A, 388, 2009, pp.1908-1916.
13. Li, W., Hiyama, T., Kobayashi, N., "Turbulence spectra in the nearneutral surface layer over the loess plateau in China". BoundaryLayer Meteorology, 124(3), 2007, pp.449-463.

14. Pal, S., Lee, T. R., Phelps, S., De Wekker, S. F. J., "Impact of atmospheric boundary layer depth variability and wind reversal on the diurnal variability of aerosol concentration at a valley site". Science of the Total Environment, 496, 2014, pp.424-434.

15. Hui, M. C. H., Larsen, A., Xiang, H. F., "Wind turbulence characteristics study at the Stonecutters Bridge site: part I: mean wind and turbulence intensities". Journal of Wind Engineering and Industrial Aerodynamic, 97, 2009, pp.22-36.

16. Hui, M. C. H., Larsen, A., Xiang, H. F., "Wind turbulence characteristics study at the Stonecutters Bridge site: part II: wind power spectra, integral length scale and coherences". Journal of Wind Engineering and Industrial Aerodynamic, 97, 2009, pp.48-59.

17. Fenerci, A., Øiseth, O., Rønnquist, A., "Long-term monitoring of wind field characteristics and dynamic response of a long-span suspension bridge in complex terrain". Engineering Structures, 147, 2017, pp.269-284.

18. Li, C. G., Liu, Y., "Research on wind field feature tests of simple canyon terrain model". Shanxi Architecture, 40(28), 2014, pp.163165. (in Chinese)

19. Hu, P., Li, Y. L., Han, Y., Cai, C. S., Xu, G. J., "Wind tunnel tests on the characteristics of wind fields over a simplified gorge". Available http://journals.sagepub.com/doi/full/10.1177/1369433216680635, 2017.

20. Hu, P., Li, Y. L., Han, Y., Cai, C. S., Xu, X. Y., "Numerical simulations of the mean wind speeds and turbulence intensities over simplified gorges using the SST k- $\omega$ turbulence model". Engineering Applications of Computational Fluid Mechanics, 10(1), 2016, pp.361-374.

21. Cao, S., Wang, T., Ge, Y., Tamura, Y., "Numerical study on turbulent boundary layers over two-dimensional hills - Effects of surface roughness and slope". Journal of Wind Engineering and Industrial Aerodynamics, 104-106, 2012, pp.342-349.

22. Chen, X., Liu, Y., "Finite Element Modeling and Simulation with ANSYS Workbench". Boca Raton: CRC Press, USA, 2014.

23. Munson, B. R., Rothmayer, A. P., Okiishi, T. H., Huebsch, W. W., "Fundamentals of Fluid Mechanics". Hoboken: Wiley, USA, 2013.

24. Hu, P., Li, Y. L., Cai, C. S., Liao, H. L., Xu, G. J., "Numerical simulation of the neutral equilibrium atmospheric boundary layer using the SST k-w turbulence model". Wind and Structures, 17(1), 2013, pp.87-105.

25. OriginLab Corporation, "Learning Resources for Origin". Available at: http://www.originlab.com/doc/User-Guide\#Introduction, 2017 